\title{
Potential Involvement of MiR-30e-3p in Myocardial Injury Induced by Coronary Microembolization via Autophagy Activation
}

\author{
Xian-tao Wang Xiao-dan Wu Yuan-xi Lu Yu-han Sun Han-hua Zhu \\ Jia-bao Liang Wen-kai He Zhi-yu Zeng Lang Li \\ Department of Cardiology, the First Affiliated Hospital of Guangxi Medical University, Nanning, China
}

\section{Key Words}

Coronary microembolization $\cdot$ MiR-30e-3p • Autophagy $\bullet$ Myocardial

\begin{abstract}
Background/Aims: Coronary microembolization (CME) can lead to no-reflow or slow reflow, which is one of the important reasons for loss of clinical benefit from myocardial reperfusion therapy. MicroRNAs and autophagy are heavily implicated in the occurrence and development of almost all cardiovascular diseases. Therefore, the present study was designed to investigate the role of miR-30e-3p and autophagy in CME-induced myocardial injury rat model. Methods: Sixty rats were randomly divided into six groups: sham, CME $1 \mathrm{~h}, 3 \mathrm{~h}, 6 \mathrm{~h}, 9 \mathrm{~h}$, and $12 \mathrm{~h}$ ( $n=10$ per group). Our CME rat model was created by injecting polyethylene microspheres $(42 \mu \mathrm{m})$ into the left ventricle of the heart; the sham group was injected with same volume of normal saline. The cardiac function and serum cardiac troponin I (cTnI) level of each group was measured. HE staining and HBFP staining were used to evaluate the myocardial micro-infarction area of myocardium tissue samples. Then RT-qPCR and western blot were used to detect the expression of miR-30e-3p and, autophagy related protein LC3-II and p62, respectively. Transmission electron microscope (TEM) was used to identify autophagic vacuoles in tissue samples. Results: The cardiac function of the CME $6 \mathrm{~h}, 9 \mathrm{~h}$, and $12 \mathrm{~h}$ groups were significantly decreased compared to the sham group $(P<0.05)$ and the cTnI level in each group were also significantly increased $(P<0.05)$. The expression of miR-30e-3p in the CME $6 \mathrm{~h}, 9 \mathrm{~h}$ and $12 \mathrm{~h}$ group were decreased significantly compared with the sham group $(P<0.05)$. Meanwhile, the expression of autophagy related protein LC3-II decreased significantly and p62 increased significantly in the CME $9 \mathrm{~h}$ and $12 \mathrm{~h}$ group $(P<0.05)$. TEM images showed typical autophagic vacuoles for each of the CME groups. Conclusions: Myocardial miR-30e-3p is down regulated after CME and is accompanied by inhibited autophagy and decreased cardiac function. Therefore, miR-30e-3p may be involved in CME-induced cardiac dysfunction by regulating myocardial autophagy.
\end{abstract}

$\mathrm{X}$. Wang and $\mathrm{X}$. Wu are co-first authors. 


\section{Introduction}

Coronary microembolization (CME) was first reported as a common complication during percutaneous coronary intervention (PCI) by Erbel [1]. CME can lead to no-reflow or slow reflow, which is one of the principal ways for loss of clinical benefit from myocardial reperfusion therapy [2-4]. CME may also result in myocardial contractile dysfunction and notable arrhythmias which are strongly associated with cardiac dysfunction and deterioration of clinical follow-ups [5-7]. Recently, research has found that microRNAs (miRs) and myocardial autophagy may play a vital role in CME $[8,9]$; however, the specific molecular mechanism of these factors remains unclear.

MiRs are endogenous non-coding small RNA molecules that regulate the expression of target genes at the post-transcriptional level, by pair-bonding with the 3'-untranslated region (3'-UTR) of a target mRNA [10]. It has been demonstrated that several miRs are associated with cardioprotection of ischemic postconditioning following myocardial ischemia/ reperfusion, such as miR-29b, -133a, and -146b [11]. Hypoxia significantly modifies the miRNA profile in the heart [12]. Notable research has also demonstrated that autophagy takes part in the occurrence and development of almost all cardiovascular diseases [13-15]. However, currently no evidence has been found of activated autophagy in left ventricular myocardium during early reperfusion with protection by remote ischemic preconditioning in patients undergoing coronary artery bypass grafting [16]. In a preliminary experiment, we used microarray analysis to identify several miRNAs that were prominently dysregulated in a rat myocardium after microsphere infusion. Among those notably downregulated was miR-30e-3p, a miR associated with cardiomyocyte autophagy and apoptosis. While, recent advances in the field have been made to understand the regulation of autophagy by the miR-30 family $[17,18]$. Remarkably, the role of miR-30e-3p in the regulation of myocardial autophagy after CME remains elusive.

In this study, we constructed a CME model in rats to observe changes in miR-30e-3p expression and myocardial autophagy after CME; as well as to investigate the relationship between myocardial injury induced by CME and myocardial autophagy level. We hypothesized that miR-30e-3p is involved in CME-induced cardiac dysfunction by regulating myocardial autophagy.

\section{Materials and Methods}

\section{Animal modeling and treatment}

All animal procedures were conducted in line with the Guide for the Care and Use of Laboratory Animals (NIH Publication No. 85-23) and were approved by the Animal Care and Use Committee of Guangxi Medical University. Healthy adult male Sprague-Dawley rats (250-300g) were purchased from the Medical Experimental Animal Center of Guangxi Medical University (Nanning, China). Sixty rats were randomized (random number) into six groups: sham, CME $1 \mathrm{~h}, 3 \mathrm{~h}, 6 \mathrm{~h}, 9 \mathrm{~h}$ and $12 \mathrm{~h}$ ( $n=10$ per group). Our study created a CME rat model by injecting plastic microspheres into the left ventricle (LV) of each rat, as previously described [19-21]. Briefly, a left thoracotomy was performed on each subject between the third and fifth intercostal space. The pericardium was stripped and the ascending aorta was exposed fully. A suspension of microspheres in saline solution containing a total of about 3, 000 microspheres ( $42 \mu \mathrm{m}$ in diameter, Biosphere Medical Inc. Rockland, USA) was injected into the LV during the 10s occlusion of the ascending aorta. Rats in the sham group received an injection of the same volume of normal saline only.

\section{Cardiac function monitoring}

Echocardiography was performed using Philips SONOS7500 at a probe frequency of $10 \mathrm{MHz}$. All echocardiographic examinations (including: the left ventricular ejection fraction (LVEF), left ventricular fractional shortening (LVFS), cardiac output (CO) and left ventricular internal diameter at end-diastole (LVIDd) )of each group were measured by a professional physician. All measures were expressed as the average of three heart beat cycles. 


\section{Cellular Physiology Cell Physiol Biochem 2017;44:1995-2004 \begin{tabular}{l|l|l} 
and Biochemistry Published online: December 11, 2017 & $\begin{array}{l}\text { (c) } 2017 \text { The Author(s). Published by S. Karger AG, Basel } \\
\text { www.karger.com/cpb }\end{array}$ \\
\hline
\end{tabular}}

\section{Measurement of serum cardiac troponin I (cTnI)}

Before each cat was sacrificed EDTA-anticoagulated blood samples were collected from the abdominal aorta. Next, the blood samples were immediately centrifugated at $3000 \mathrm{rpm}$ for $15 \mathrm{~min}$, and the separated serum was collected and stored at $-80^{\circ} \mathrm{C}$. The level of cTnI protein in serum was measured by a light absorption microplate reader using a rat cTnI Enzyme-linked Immuno Sorbent Assay (ELISA) kit (Roche, Inc., Switzerland). All operations were carried out in strict accordance with the manufacturer's instructions and the OD value was measured at a wavelength of $450 \mathrm{~nm}$. A standard curve was established from the absorbance readings to calculate the concentration of cTnI in each sample.

\section{Tissue sampling and pathological examination}

After cardiac function evaluations, the rats were euthanized. The hearts were collected and washed immediately three times with cold normal saline. The atrial appendage and atrium cordis were removed, and these parts of the heart ventricle were rapidly frozen in liquid nitrogen and stored at $-80{ }^{\circ} \mathrm{C}$ for western blot analysis and qPCR. The rest were fixed in 4\% paraformaldehyde for 12 hours, embedded in paraffin and serially sectioned into $4 \mu \mathrm{m}$ slices for HE staining and hematoxylin-basic fuchsin-picric acid (HBFP) staining.

\section{Size measurement of myocardial micro-infarct}

Early myocardial ischemia or infarct regions was visualized using HBFP staining [20]. The ischemia or necrotic myocardial tissue were dyed red while the normal myocardial tissue was yellow or brown. HBFP-stained slices were analyzed by a DMR-Q550 pathological image analyzer (Leica, Germany). Briefly, five microscopic visual fields (magnification, x 200) were randomly sampled from each slice, four slices per sample, for observation using Leica Qwin image analysis software. The area of micro-infarction was determined by planimetry and expressed as percentage of the total analyzed area.

\section{RNA extraction and quantitative RT-PCR}

Total RNA was isolated from left ventricular myocardium using the TRIzol reagent (Gibco, USA) according to the protocols supplied by the manufacturers. The concentration of RNA was quantified using a NanoDrop (Thermo Fisher Scientific Inc., USA) and then subjected to reverse transcription by a cDNA reverse transcription kit (TaKaRa, Japan) according to the manufacturer's instructions. Then, the cDNA was analyzed with RT-qPCR specifically for miR-30e-3p using a SYBR Green I PCR kit (TaKaRa, Japan), with U6 DNA as an internal control. The conditions for all RT-qPCR reactions were performed on the ABI PRISM 7500 system (Applied BioSystems, USA). The sequences of the primers were designed as following: miR30e-3p forward: 5' - GGGCTTTCAGTCGGATGTT-3' and reverse: 5'- GTGCGTGTCGTGGAGTCG-3'; U6 forward: 5'- GCTTCGGCAGCACATATACTAAAAT-3' and reverse: 5'- CGCTTCACGAATTTGCGTGTCAT-3'. The relative quantification of miR-30e-3p was calculated using the $2^{-\Delta \Delta \mathrm{Ct}}$ method and was normalized using the U6 results.

\section{Western blotting}

Protein samples were extracted from left ventricular myocardium using the Protein Extracion Kit (Solarbio, China). The protein concentrations were determined using the bicinchoninic acid (BCA) protein assay (Beyotime Biotechnology, China). Equal amounts (50 $\mu \mathrm{g}$ ) of protein were loaded on 10\% SDS-PAGE and transferred to a PVDF membrane (Millipore). After blocking the membrane with 5\% non-fat milk in TBS for $1 \mathrm{~h}$ at room temperature, the membranes were incubated with the following primary antibodies overnight at $4{ }^{\circ} \mathrm{C}$ : anti- LC3-II, anti-p62 and anti-GAPDH (all from CST, USA). GAPDH was used as an internal control. After washing 3 times with TBST, the membranes were incubated with the appropriate infrared secondary antibodies (Abcam, USA) in the dark for $2 \mathrm{~h}$ at room temperature. Finally, the protein bands intensity was analyzed using Odyssey infrared fluorescence scanning imaging system (Odyssey, LICOR, USA).

\section{Transmission Electron Microscope (TEM)}

Myocardial tissues were fixed with $2.5 \%$ glutaraldehyde and were cut into $1 \mathrm{~mm}$ x $1 \mathrm{~mm}$ x $1 \mathrm{~mm}$ pieces. Then, the tissues were cleaned, dehydrated, embedded, sliced, stained, and subsequently observed using a transmission electron microscope (Hitachi H-7650, Japan). All examinations were performed under 30, 000x magnification by a pathologist who was blinded to study grouping. The myofibrillar structure, mitochondrial membrane and typical autophagic vacuoles of each tissue sample were observed. 
Table 1. Changes in cardiac function following CME. Abbreviations: CME, coronary microembolization; LVEF, left ventricular ejection fraction; LVFS, left ventricular fractional shortening; CO, cardiac output; LVIDd, left ventricular internal diameter at enddiastole. Data are presented as mean \pm S.D. ${ }^{\text {a }}<0.05$ versus the sham group

\begin{tabular}{|c|c|c|c|c|c|}
\hline froun & n & LVEF(\%) & LVFS(\%) & $\mathrm{Co}(\mathrm{L} / \mathrm{min})$ & LVIDd(mm) \\
\hline & 10 & $84.61+2.67$ & $52.06+2.66$ & $0.2 .1+0.0 .3 .3$ & $5.88+0.39$ \\
\hline $1 \mathrm{~h}$ & 10 & $84.37 \pm 3.18$ & $52.35 \pm 3.61$ & \pm 0.042 & 0.51 \\
\hline $3 \mathrm{~h}$ & 10 & $82.57 \pm 3.08$ & $51.49 \pm 2.51$ & $0.21 \pm 0.039$ & $6.19 \pm 0.44$ \\
\hline CME $6 \mathrm{~h}$ & 10 & $69.16 \pm 4.45$ & $37.88 \pm 2.07$ & $0.17 \pm 0.026$ & $6.70 \pm 0.61$ \\
\hline CME $9 \mathrm{~h}$ & 10 & $55.47 \pm 3.58^{\mathrm{a}}$ & $26.16 \pm 1.62^{a}$ & $0.12 \pm 0.025^{\mathrm{a}}$ & $7.33 \pm 0.58^{\mathrm{a}}$ \\
\hline CME $12 \mathrm{~h}$ & 10 & $56.28+4.39 a$ & $25.83+1.43 a$ & $0.13+0.019 a$ & $7.30+0.60 \mathrm{a}$ \\
\hline
\end{tabular}

Table 2. Serum cTnI concentrations following CME. Abbreviations: CME, coronary microembolization; cTnI, cardiac troponin I. Data are presented as mean \pm S.D. ${ }^{\text {ap }}<0.05$ versus the sham group

\begin{tabular}{lc}
\hline Group & cTnI \\
\hline Sham & $30.28 \pm 8.13$ \\
CME $1 \mathrm{~h}$ & $34.39 \pm 8.87$ \\
CME 3h & $78.01 \pm 10.20^{\mathrm{a}}$ \\
CME 6h & $95.33 \pm 12.54^{\mathrm{a}}$ \\
CME 9h & $112.87 \pm 18.38^{\mathrm{a}}$ \\
CME $12 \mathrm{~h}$ & $110.19 \pm 17.65^{\mathrm{a}}$ \\
\hline
\end{tabular}

\section{Statistical analysis}

All statistical data are presented as mean \pm standard deviation (SD). Differences between multiple groups were analyzed by a one-way analysis of variance (ANOVA) with a Tukey's test for post hoc analysis, using SPSS 21.0 for Windows (SPSS Inc., USA). All experiments were performed independently and in triplicate. Values of $P<0.05$ were considered to be statistically significant.

\section{Results}

\section{Changes in cardiac function}

Compared with the sham group, the cardiac function at $6 \mathrm{~h}, 9 \mathrm{~h}$ and $12 \mathrm{~h}$ in the CME group were significantly decreased. The specific performances were left ventricular systolic dysfunction and left ventricular dilation: LVEF, LVFS, decreased $\mathrm{CO}$, while LVIDd was increased as seen in Table 1 and Fig. 1.

\section{Detection of myocardial injury marker cTnI}

As shown in Table 2 and Fig. 2, the cTnI levels of all CME groups were significantly increased except for the $1 \mathrm{~h}$ group compared with the sham group $(P<0.05)$. The level of serum cTnI rapidly increased as early as $3 \mathrm{~h}$ after CME modeling and reached the peak value at $9 \mathrm{~h}$.

Histopathology of myocardial microinfarct following CME

Except for the sham group, HE staining of myocardial tissue in all other

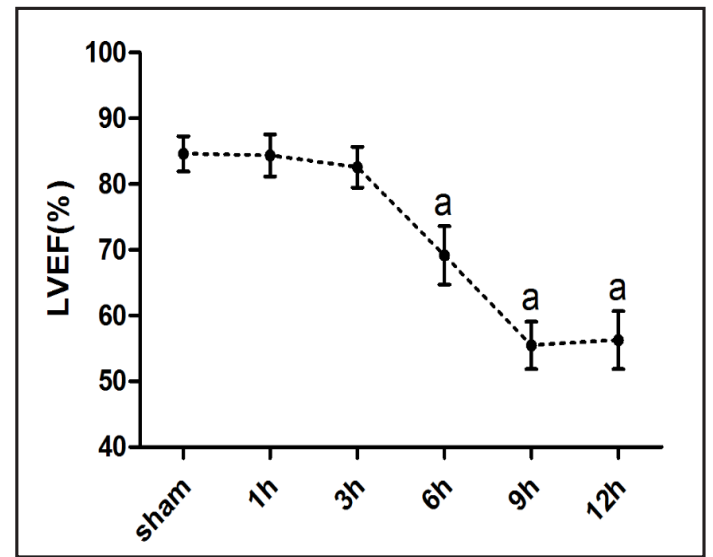

Fig. 1. Dynamic changes of LVEF at different timepoints after $\mathrm{CME}$ modeling. ${ }^{\mathrm{a}} \mathrm{P}<0.05$ versus the sham group.

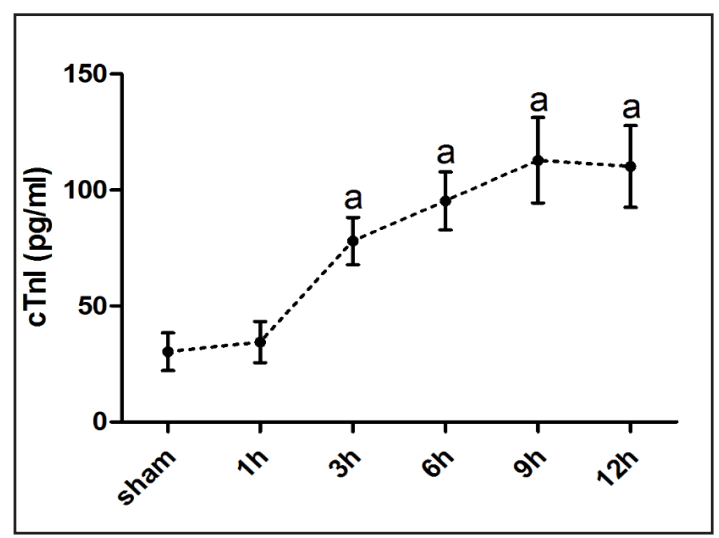

Fig. 2. Dynamic changes in cTnI concentration in CME model. ${ }^{\text {a }}<0.05$ versus the sham group. 
Fig. 3. HE staining of micro-infarct focus in a CME model. The arrow indicates microsphere in arteriole ( $\mathrm{x} 200$, Scale bar $=50 \mu \mathrm{m}) . \mathrm{A}$, CME group; B, Sham group.

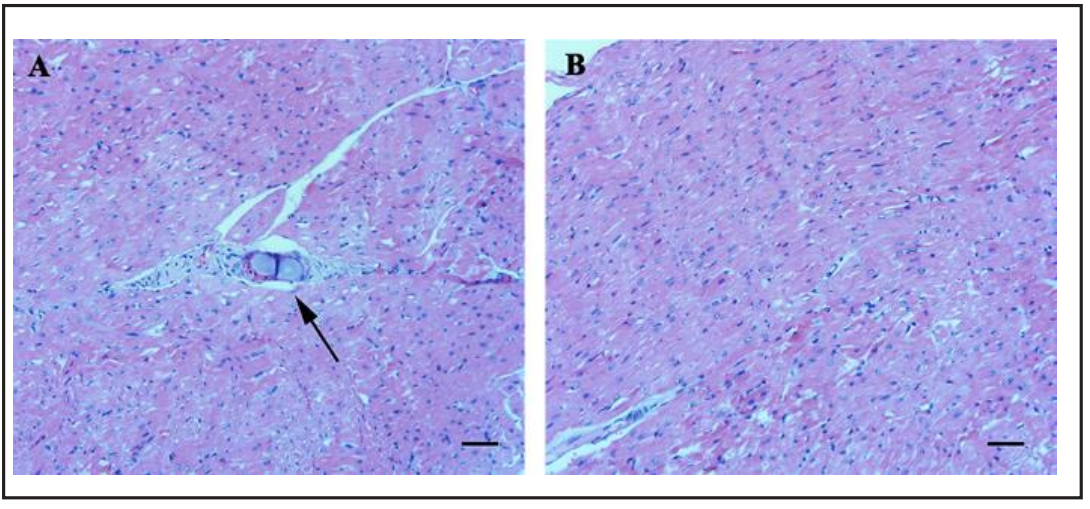

Fig. 4. Micro-infarct measurement with HBFP staining (magnification, x 200; Scale bar $=50 \mu \mathrm{m}$ ). Normal myocardium is stained yellow, while the ischemic myocardium is stained red. Arrows indicate micro-infarct focus. A, CME group; B, Sham group.

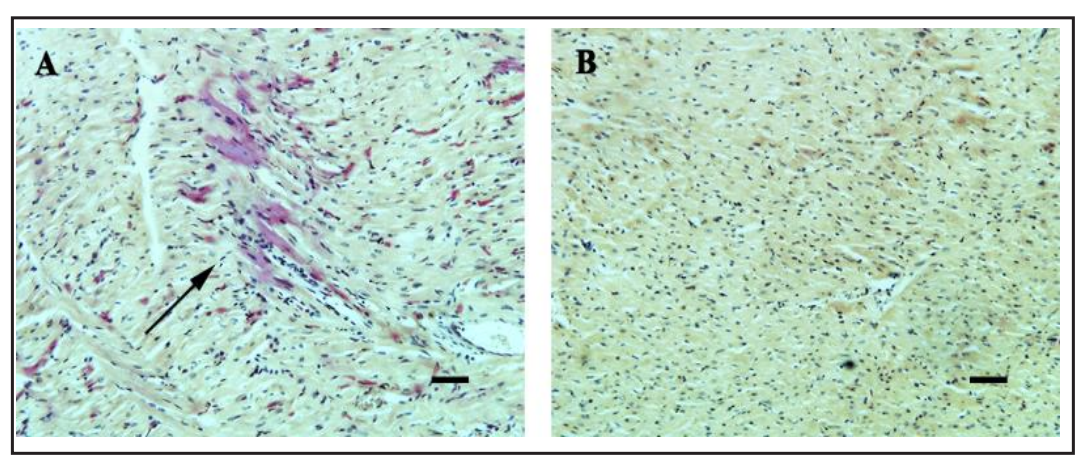

Fig. 5. Dynamic changes in miR-30e-3p expression in myocardium detected by RT-qPCR. The data were obtained from at least three independent experiments and the values represent the means \pm S.D. ${ }^{\text {a }} \mathrm{P}<0.05$ versus the sham group.

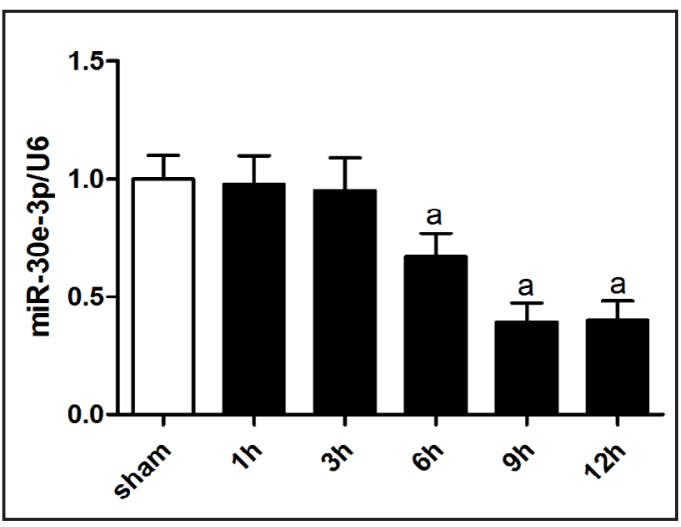

groups showed dissolved or disappeared myocardial nuclear around the focus of the microembolism and myocardial tissue had edema degeneration accompanied by a large number of inflammatory cell infiltrates (Fig. 3). HBFP staining was performed to determine the presence of myocardial micro-infarction (Fig. 4). HBFP staining showed that the myocardial micro-infarct zone was red while the unaffected tissue was yellow. The nucleus was stained blue and micro-infarction focuses were primarily focally distributed. The microinfarction size of CME $3 \mathrm{~h}, 6 \mathrm{~h}, 9 \mathrm{~h}$ and $12 \mathrm{~h}$ group were $(13.59 \pm 3.11) \%$, $(14.82 \pm 2.61) \%$, $(15.05 \pm 2.02) \%$ and $(14.11 \pm 3.24) \%$, respectively, with no significant differences among the groups. No micro-infarcts were found in the sham group.

\section{Expression of $\mathrm{miR}-30 e-3 p$}

RT-qPCR analysis was performed to observe any expression of miR-30e-3p in the rat myocardium (Fig. 5). Compared with the sham group, the expression of miR-30e-3p in CME $6 \mathrm{~h}, 9 \mathrm{~h}$ and $12 \mathrm{~h}$ groups were decreased significantly after CME in rats $(P<0.05)$, but not in CME $1 \mathrm{~h}$ and $3 \mathrm{~h}$ group.

\section{KARGER}


Fig. 6. LC3-II protein expression detected by western blot. The data were obtained from at least three independent experiments and the values represent the means \pm S.D. ${ }^{\text {a }} \mathrm{P}<0.05$ and ${ }^{b} \mathrm{P}<0.01$ versus the sham group.

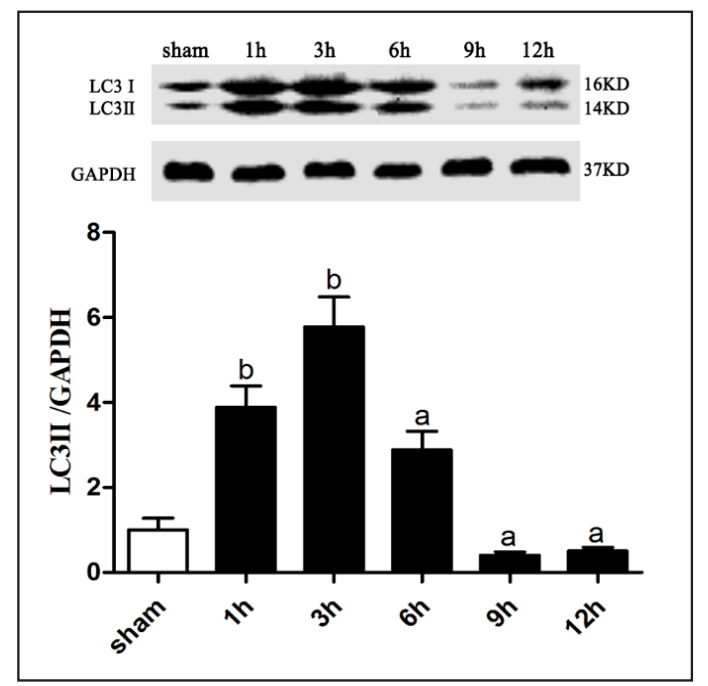

Fig. 7. p62 protein expression detected by western blot. The data were obtained from at least three independent experiments and the values represent the means \pm S.D. ${ }^{\text {a }} \mathrm{P}<0.05$ and ${ }^{b} \mathrm{P}<0.01$ versus the sham group.

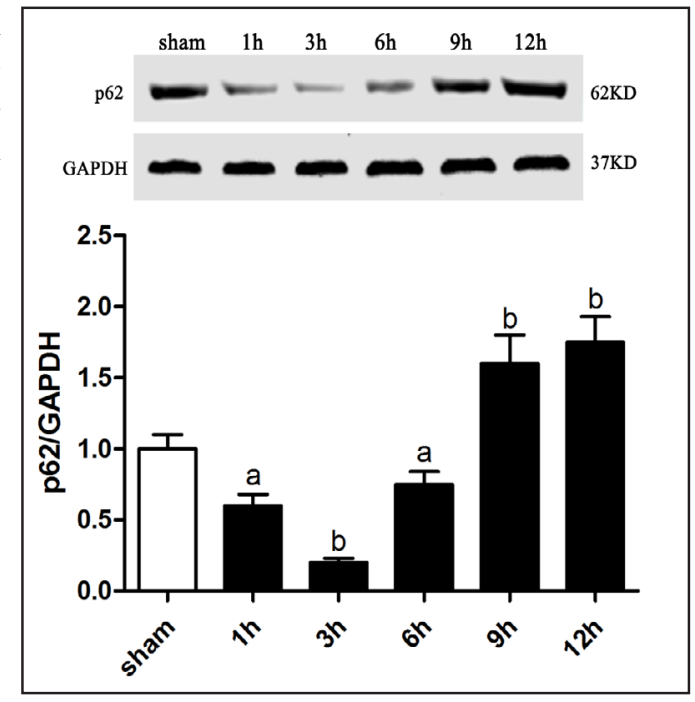

Expression of LC3-II and p62 proteins

LC3-II and p62 are two typical autophagy-related proteins, therefore, the LC3- II and p62 expression in myocardial were investigated by western blot analysis (Fig. 6, 7 respectively). Compared with the sham group, the expression of LC3-II protein was increased significantly and the expression of the p62 protein was decreased significantly in the group CME $1 \mathrm{~h}, 3 \mathrm{~h}$, and $6 \mathrm{~h}(P<0.05)$; while the expression of LC3II protein was decreased significantly and the expression of p62 protein was increased significantly in the group CME $9 \mathrm{~h}$ and $12 \mathrm{~h}(P<$ 0.05).

\section{Transmission Electron Microscopy observation}

Our TEM observation revealed that the myofibrillar structure was normal and the mitochondrial membrane integrity was maintained in the sham group; while myofibril fragmentation, mitochondrial swelling, and the double-layer membrane structure of typical autophagic vacuoles were visible in the CME group. The number of autophagic vacuoles was dramatically increased in the CME 3h group, while considerably decreased in the CME $9 \mathrm{~h}$ group compared with the sham group (Fig. 8). 


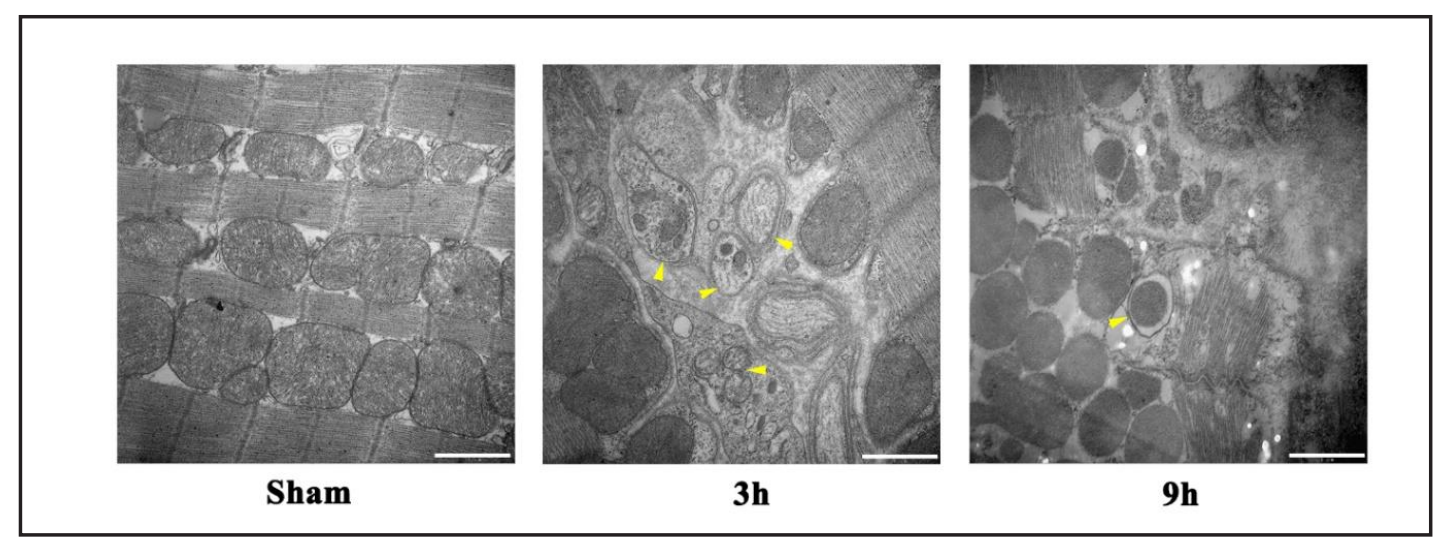

Fig. 8. Image of autophagic vacuole in myocardium taken by transmission electron microscope. The arrow indicates typical autophagic vacuoles $(x 30,000$, Scale bar $=1 \mu \mathrm{m})$.

\section{Discussion}

Our study was designed to elucidate the changes in miR-30e-3p expression and autophagy in myocardial injury induced by CME and to investigate the relationship between cardiac dysfunction and myocardial autophagy level by establishing a CME model in rats. The results reveal that myocardial injury, cardiac dysfunction and micro-infarct are induced following CME. In the rat myocardium of our CME model, the expression of miR-30e-3p was down regulated and accompanied by inhibition of autophagy and decreased cardiac function. MiR-30e-3p may be involved in CME-induced cardiac dysfunction by regulating myocardial autophagy.

CME is defined as coronary microcirculation thrombosis and micro-infarction caused when an atherosclerotic plaque ruptures spontaneously or microemboli in patients undergoing PCI [22]. CME may occur during thrombolytic therapy and coronary interventions, resulting in serious clinical issues including contractile dysfunction, malignant arrhythmias and even sudden cardiac death $[1,23]$. How to accurately assess and effectively prevent CME has proven to be a complex problem for interventional cardiovascular physicians.

MiR-30e-3p belongs to the miR-30 family of miRs, which includes miR-30a, miR-30b, miR-30c, miR-30d and miR-30e. The heart can abundantly express miR-30 family members which are widely involved in the pathophysiology of various heart diseases [24-26]. In the field of cardiac research, research on the miR-30 family is mainly focused on myocardial hypertrophy, myocardial infarction, heart failure and ischemia reperfusion injury [27-29]. The miR-30 family also plays an important role in the inhibition of cardiac ischemic injury [30]. The results of this study showed that mi-30e-3p expression is significantly decreased after CME, meanwhile, myocardial autophagy is dramatically inhibited.

Myocardial autophagy is involved in almost all diseases of heart and affect the occurrence and development of the such disease. The inhibition of autophagy has been shown to aggravate myocardial hypertrophy in cardiac hypertrophy [31]. Additionally, increased autophagy can lead to autophagic death of cardiomyocytes in heart failure and reduce infarct sizes in myocardial infarction [32,33]. Normal autophagy flux is a determinant factor of cardiomyocyte survival following ischemia reperfusion injury [34]. Autophagy regulation is expected to be a novel therapeutic target for cardiovascular disease. Our research shows that the reduction in autophagy level is consistent with a decrease in cardiac function.

Research on the regulation of myocardial autophagy by the mir-30 family has also made important progress recently. Yang and colleagues discovered that exosomal transfer of miR30 a between cardiomyocytes regulates autophagy after hypoxia [18]. Li and colleagues then found that upregulation of miR-30a protects cardiac myocytes from ischemia reperfusion injury [17]. Another study showed that miR-30-regulated autophagy mediates angiotensin II-induced myocardial hypertrophy [35]. 


\section{Cellular Physiology Cell Physiol Biochem 2017;44:1995-2004 \begin{tabular}{l|l|l} 
and Biochemistry & $\begin{array}{l}\text { DOI: 10.1159/000485905 } \\
\text { Published online: December 11, } 2017\end{array}$ & $\begin{array}{l}\text { C) } 2017 \text { The Author(s). Published by S. Karger AG, Basel } \\
\text { www.karger.com/cpb }\end{array}$
\end{tabular}}

The present study focused on CME induced myocardial injury and investigated the possible underlying mechanisms. CME induced myocardial injury was shown to be associated with a decrease in miR-30e-3p expression which induced myocardial autophagy inhibition. These findings may provide new therapeutic options for myocardial injury in CME-induced cardiac dysfunction.

The limitations of this study should be acknowledged. Our results were derived from a rat CME model which was made by injecting plastic microspheres into the $\mathrm{LV}$. Therefore, these data may not be directly comparable with those obtained from in vivo microembolization enriched with platelets, red blood cells and other bioactive factors. Considering this point, future studies are required to explore our findings in an animal model that closely mimics human biology.

\section{Conclusion}

Our results indicate that miR-30e-3p is down regulated in the myocardium after a CME event and this is accompanied by inhibited autophagy and a decrease in cardiac function. MiR-30e-3p may be involved in CME-induced cardiac dysfunction by regulating myocardial autophagy.

\section{Acknowledgements}

This work was supported by National Natural Science Foundation of China (Grant No.81770346) and Appropriate Technology for Health Care Research and Development Projects of Guangxi, China (Grant No. S2015 21).

\section{Disclosure Statement}

No competing financial interests exist for any of the authors.

\section{References}

-1 Erbel R, Heusch G: Coronary microembolization. J Am Coll Cardiol 2000;36:22-24.

2 Jaffe R, Charron T, Puley G, Dick A, Strauss BH: Microvascular obstruction and the no-reflow phenomenon after percutaneous coronary intervention. Circulation 2008;117:3152-3156.

-3 Niccoli G, Burzotta F, Galiuto L, Crea F: Myocardial no-reflow in humans. J Am Coll Cardiol 2009;54:281292.

Heusch G: The coronary circulation as a target of cardioprotection. Circ Res 2016;118:1643-1658.

Bolognese L, Carrabba N, Parodi G, Santoro GM, Buonamici P, Cerisano G, Antoniucci D: Impact of microvascular dysfunction on left ventricular remodeling and long-term clinical outcome after primary coronary angioplasty for acute myocardial infarction. Circulation 2004;109:1121-1126.

6 Galiuto L, Garramone B, Scara A, Rebuzzi AG, Crea F, La Torre G, Funaro S, Madonna M, Fedele F, Agati L: The extent of microvascular damage during myocardial contrast echocardiography is superior to other known indexes of post-infarct reperfusion in predicting left ventricular remodeling: Results of the multicenter amici study. J Am Coll Cardiol 2008;51:552-559.

7 Wu X, Mintz GS, Xu K, Lansky AJ, Witzenbichler B, Guagliumi G, Brodie B, Kellett MA, Jr., Dressler O, Parise H, Mehran R, Stone GW, Maehara A: The relationship between attenuated plaque identified by intravascular ultrasound and no-reflow after stenting in acute myocardial infarction: The horizons-ami (harmonizing outcomes with revascularization and stents in acute myocardial infarction) trial. JACC Cardiovasc Interv 2011;4:495-502. 


\section{Cellular Physiology Cell Physiol Biochem 2017;44:1995-2004 \begin{tabular}{l|l|l} 
and Biochemistry Published online: December 11, 2017 & $\begin{array}{l}\text { (c) } 2017 \text { The Author(s). Published by S. Karger AG, Basel } \\
\text { www.karger.com/cpb }\end{array}$ \\
\hline
\end{tabular}}

8 Gao YH, Qian JY, Chen ZW, Fu MQ, Xu JF, Xia Y, Ding XF, Yang XD, Cao YY, Zou YZ, Ren J, Sun AJ, Ge JB: Suppression of bim by microrna-19a may protect cardiomyocytes against hypoxia-induced cell death via autophagy activation. Toxicol Lett 2016;257:72-83.

-9 Su Q Li L, Liu Y, Zhou Y, Wang J, Wen W: Ultrasound-targeted microbubble destruction-mediated microrna-21 transfection regulated pdcd4/nf-kappab/tnf-alpha pathway to prevent coronary microembolization-induced cardiac dysfunction. Gene Therapy 2015;22:1000-1006.

-10 Bartel DP: Micrornas: Genomics, biogenesis, mechanism, and function. Cell 2004;116:281-297.

11 Baars T, Skyschally A, Klein-Hitpass L, Cario E, Erbel R, Heusch G, Kleinbongard P: Microrna expression and its potential role in cardioprotection by ischemic postconditioning in pigs. Pflugers Arch 2014;466:19531961.

12 Zhi F, Xue L, Shao N, Deng D, Kang X, Chao D, Xu Y, Wang R, Yang Y, Xia Y: Delta-opioid receptor activation and microrna expression in the rat heart under prolonged hypoxia. Cell Physiol Biochem 2016;39:11181128.

13 Ucar A, Gupta SK, Fiedler J, Erikci E, Kardasinski M, Batkai S, Dangwal S, Kumarswamy R, Bang C, Holzmann A, Remke J, Caprio M, Jentzsch C, Engelhardt S, Geisendorf S, Glas C, Hofmann TG, Nessling M, Richter K, Schiffer M, Carrier L, Napp LC, Bauersachs J, Chowdhury K, Thum T: The mirna-212/132 family regulates both cardiac hypertrophy and cardiomyocyte autophagy. Nat Commun 2012;3:1078.

14 Su M, Wang J, Wang C, Wang X, Dong W, Qiu W, Wang Y, Zhao X, Zou Y, Song L, Zhang L, Hui R: Microrna-221 inhibits autophagy and promotes heart failure by modulating the p27/cdk2/mtor axis. Cell Death Differ 2015;22:986-999.

15 Higashi K, Yamada Y, Minatoguchi S, Baba S, Iwasa M, Kanamori H, Kawasaki M, Nishigaki K, Takemura G, Kumazaki M, Akao Y, Minatoguchi S: Microrna-145 repairs infarcted myocardium by accelerating cardiomyocyte autophagy. Am J Physiol Heart Circ Physiol 2015;309:H1813-1826.

16 Gedik N, Thielmann M, Kottenberg E, Peters J, Jakob H, Heusch G, Kleinbongard P: No evidence for activated autophagy in left ventricular myocardium at early reperfusion with protection by remote ischemic preconditioning in patients undergoing coronary artery bypass grafting. PLoS One 2014;9:e96567.

$\checkmark 17$ Li D, Wang J, Hou J, Fu J, Liu J, Lin R: Salvianolic acid b induced upregulation of mir-30a protects cardiac myocytes from ischemia/reperfusion injury. BMC Complement Altern Med 2016;16:336.

18 Yang Y, Li Y, Chen X, Cheng X, Liao Y, Yu X: Exosomal transfer of mir-30a between cardiomyocytes regulates autophagy after hypoxia. J Mol Med (Berl) 2016;94:711-724.

19 Li L, Li DH, Qu N, Wen WM, Huang WQ: The role of erk1/2 signaling pathway in coronary microembolization-induced rat myocardial inflammation and injury. Cardiology 2010;117:207-215.

20 Wang XT, Lu YX, Sun YH, He WK, Liang JB, Li L: Tak-242 protects against apoptosis in coronary microembolization-induced myocardial injury in rats by suppressing tlr4/nf-kappab signaling pathway. Cell Physiol Biochem 2017;41:1675-1683.

21 Dorge H, Neumann T, Behrends M, Skyschally A, Schulz R, Kasper C, Erbel R, Heusch G: Perfusioncontraction mismatch with coronary microvascular obstruction: Role of inflammation. Am J Physiol Heart Circ Physiol 2000;279:H2587-2592.

22 Heusch G, Kleinbongard P, Bose D, Levkau B, Haude M, Schulz R, Erbel R: Coronary microembolization: From bedside to bench and back to bedside. Circulation 2009;120:1822-1836.

23 Morishima I, Sone T, Okumura K, Tsuboi H, Kondo J, Mukawa H, Matsui H, Toki Y, Ito T, Hayakawa T: Angiographic no-reflow phenomenon as a predictor of adverse long-term outcome in patients treated with percutaneous transluminal coronary angioplasty for first acute myocardial infarction. J Am Coll Cardiol 2000;36:1202-1209.

24 McManus MT, Li J, Donath S, Li Y, Qin D, Prabhakar BS, Li P: Mir-30 regulates mitochondrial fission through targeting p53 and the dynamin-related protein-1 pathway. PLoS Genetics 2010;6.

25 Zhang T, Tian F, Wang J, Jing J, Zhou SS, Chen YD: Endothelial cell autophagy in atherosclerosis is regulated by mir-30-mediated translational control of atg6 Cell Physiol Biochem 2015;37:1369-1378.

26 Chen M, Ma G, Yue Y, Wei Y, Li Q Tong Z, Zhang L, Miao G, Zhang J: Downregulation of the mir-30 family micrornas contributes to endoplasmic reticulum stress in cardiac muscle and vascular smooth muscle cells. Int J Cardiol 2014;173:65-73. 


\section{Cellular Physiology Cell Physiol Biochem 2017;44:1995-2004 \begin{tabular}{l|l} 
DOI: 10.1159/000485905 & $\begin{array}{l}\text { O 2017 The Author(s). Published by S. Karger AG, Basel } \\
\text { www.karger.com/cpb }\end{array}$ \\
\hline
\end{tabular}

27 Duisters RF, Tijsen AJ, Schroen B, Leenders JJ, Lentink V, van der Made I, Herias V, van Leeuwen RE, Schellings MW, Barenbrug P, Maessen JG, Heymans S, Pinto YM, Creemers EE: Mir-133 and mir-30 regulate connective tissue growth factor: Implications for a role of micrornas in myocardial matrix remodeling. Circ Res 2009;104:170-178.

-28 Long G, Wang F, Duan Q, Yang S, Chen F, Gong W, Yang X, Wang Y, Chen C, Wang DW: Circulating mir-30a, mir-195 and let-7b associated with acute myocardial infarction. PLoS One 2012;7:e50926.

29 Saddic LA, Muehlschlegel JD: Sarco"mir" friend or foe: A perspective on the mechanisms of doxorubicininduced cardiomyopathy. Ann Transl Med 2016;4:203.

-30 Shen Y, Shen Z, Miao L, Xin X, Lin S, Zhu Y, Guo W, Zhu YZ: Mirna-30 family inhibition protects against cardiac ischemic injury by regulating cystathionine-gamma-lyase expression. Antioxid Redox Signal 2015;22:224-240.

-31 Nakai A, Yamaguchi O, Takeda T, Higuchi Y, Hikoso S, Taniike M, Omiya S, Mizote I, Matsumura Y, Asahi M, Nishida K, Hori M, Mizushima N, Otsu K: The role of autophagy in cardiomyocytes in the basal state and in response to hemodynamic stress. Nat Med 2007;13:619-624.

-32 Fidzianska A, Bilinska ZT, Walczak E, Witkowski A, Chojnowska L: Autophagy in transition from hypertrophic cardiomyopathy to heart failure. J Electron Microsc (Tokyo) 2010;59:181-183.

-33 Buss SJ, Riffel JH, Katus HA, Hardt SE: Augmentation of autophagy by mtor-inhibition in myocardial infarction: When size matters. Autophagy 2010;6:304-306.

-34 Ma X, Liu H, Foyil SR, Godar RJ, Weinheimer CJ, Hill JA, Diwan A: Impaired autophagosome clearance contributes to cardiomyocyte death in ischemia/reperfusion injury. Circulation 2012;125:3170-3181.

35 Pan W, Zhong Y, Cheng C, Liu B, Wang L, Li A, Xiong L, Liu S: Mir-30-regulated autophagy mediates angiotensin ii-induced myocardial hypertrophy. PLoS One 2013;8:e53950 